\title{
Does free or lower cost smoking cessation medication stimulate quitting? Findings from the International Tobacco Control (ITC) Netherlands and UK Surveys
}

\author{
Floor A van den Brand, ${ }^{1}$ Gera E Nagelhout, ${ }^{1,2,3}$ Karin Hummel, ${ }^{2}$ Marc C Willemsen, ${ }^{2,4}$ \\ Ann McNeill, ${ }^{5}$ Onno C P van Schayck'
}

\begin{abstract}
- Additional material is published online only. To view please visit the journal online (http://dx.doi.org/10.1136/ tobaccocontrol-2017-054023).

${ }^{1}$ Department of Family Medicine, Maastricht University (CAPHRI), Maastricht, The Netherlands ${ }^{2}$ Department of Health Promotion, Maastricht University (CAPHRI), Maastricht, The Netherlands

${ }^{3}$ IVO Addiction Research Institute, The Hague, The Netherlands

${ }^{4}$ Netherlands Expertise Center for Tobacco Control (NET), Trimbos Institute, Utrecht, The Netherlands

${ }^{5}$ Department of Addictions, Institute of Psychiatry, Psychology, and Neuroscience, King's College London, London, UK
\end{abstract}

\section{Correspondence to}

Dr Floor A van den Brand, Department of Family Medicine, Maastricht University (CAPHRI), Maastricht, The Netherlands;

f.vandenbrand@

maastrichtuniversity.nl

Received 12 September 2017 Revised 25 January 2018 Accepted 7 March 2018 Published Online First 4 April 2018

\section{ABSTRACT}

Objective To investigate whether mentioning free or lower cost smoking cessation medication as a trigger for thinking about quitting is related to higher medication use, more quit attempts and quit success, and whether these associations are modified by education and income. Methods Data were derived from the 2013 and 2014 surveys of the International Tobacco Control Netherlands ( $n=1164)$ and UK $(n=768)$ cohort. Logistic regression analyses were used to assess associations between mentioning in 2013 that free/lower cost smoking cessation medication was a trigger for thinking about quitting smoking and the use of medication, quit attempts and smoking cessation in 2014.

Results $37.0 \%$ of smokers in the UK and $24.9 \%$ of smokers in the Netherlands mentioned free/lower cost medication as a trigger for thinking about quitting. Smokers who mentioned this trigger were more likely to have used cessation medication during a quit attempt both in the UK $(O R=4.19, p<0.001)$ and in the Netherlands $(O R=2.14$, $p=0.033$ ). The association between mentioning free/lower cost medication as a trigger for thinking about quitting and actual quit attempts was significant in the UK $(O R=1.45$, $p=0.030$ ), but not in the Netherlands ( $O R=1.10, p=0.587$ ). There was no significant association with quit success. Associations did not differ across income and education groups.

Conclusion Free/lower cost smoking cessation medication may increase the use of cessation medication and stimulate quit attempts among smokers with low, moderate and high education and income.

\section{INTRODUCTION}

In Western countries, the proportion of smokers is not equally divided among low and high socioeconomic groups. ${ }^{1-3}$ Individuals with lower education and income are more likely to smoke and smoke more cigarettes a day than higher educated and more affluent people. ${ }^{45}$ This disparity causes smoking to be the largest contributor to socioeconomic differences in health and mortality observed in Western countries. ${ }^{67}$ Although the proportion of people who smoke is generally declining, inequalities according to socioeconomic status (SES) have sustained or increased over time..$^{23-11}$ In the UK, $21 \%$ of individuals with no formal qualifications smoke compared with $9 \%$ of individuals with a degree. ${ }^{12}$ In the Netherlands (NL), a comparable SES gap in smoking prevalence exists: $28 \%$ of lower educated adults smoke compared with $19 \%$ of higher educated adults. ${ }^{13}$ In order to reduce this socioeconomic gap, it is vital to develop methods and policies effective for smokers with a lower SES.

Having to pay for smoking cessation treatment like bupropion, varenicline or nicotine replacement therapy-from hereon referred to as 'cessation medication'-can be a barrier for seeking treatment, particularly for people on a low income. ${ }^{14}$ More smokers use cessation medication when it is costfree, ${ }^{15}$ and this can substantially increase the number of long-term quitters. ${ }^{16}$ In a study based on data from the International Tobacco Control (ITC) Europe surveys, respondents with lower education and income mentioned the availability of free/lower cost medication more often as a trigger for thinking about quitting smoking than other education and income groups. ${ }^{17}$ Still, mentioning free/lower cost medication as a trigger for thinking about quitting does not necessarily lead to more use of medication, nor to more quit attempts and a greater likelihood of quit success. Data from the ITC Four Country surveys ${ }^{18}$ suggested that mentioning free/lower cost medication as a trigger to think about quitting was positively associated with making a quit attempt. Yet, it was not examined whether this association was dependent on respondents' income or education. Furthermore, it was not assessed whether free/lower cost medication as a trigger was associated with actual use of cessation medication and quit success.

In the current study, the ITC data from the UK and the NL are used to investigate SES differences in mentioning free/lower cost medication as a trigger to think about quitting smoking and quitting behaviour. The cultural and economic similarities of the UK and the NL make it interesting to compare these two countries. In both countries, smokers have the opportunity to receive free/lower cost smoking cessation treatment. In the UK, the National Health Service provides smokers with free or subsidised cessation medication (dependent on smokers' income) by trained practitioners in routine practice and via the stop-smoking services; behavioural support can also be obtained free via the stop-smoking services for all. ${ }^{1920}$ Stop-smoking services vary across the UK but the standard model of treatment is an assessment before quitting which takes place about a week later, and then weekly sessions until 4 weeks after the quit date. ${ }^{21}$ In the NL, pharmacotherapy can be reimbursed once every year by the Dutch health insurance system only in combination with behavioural therapy, irrespective of treatment completion or outcome. There are possibilities for receiving behavioural therapy, such as the general practitioner, outpatient services or independent healthcare 
providers registered in the Dutch quality register for scientifically proven effective smoking cessation treatment. Still, reimbursement applies only after patients have spent a mandatory deductible for general healthcare costs (at least $€ 350$ in 2013).

The aim of this study is to investigate whether in the UK and the NL free/lower cost cessation medication mentioned as a trigger for thinking about quitting is related to use of medication, quit attempts and quit success and whether these associations are modified by education and income. It is hypothesised that smokers who mentioned free or lower cost medication as a trigger were more likely to make a quit attempt, to use cessation medication and had higher quit rates. Moreover, it is expected that this association is stronger for smokers with lower income and education than smokers with higher income and education, as the cost of cessation treatment has been mentioned as a barrier to quitting smoking by smokers with lower income and education. ${ }^{22} 23$

\section{METHODS}

Data were used from the 2013 and 2014 surveys of the ITC NL and UK cohorts. The ITC Project is a prospective cohort study of a representative sample of smokers and ex-smokers in each country. ${ }^{24}$ Survey data were collected by web (59\%) and telephone (41\%) for the UK and by web only for the NL. Surveys were collected from February to September 2013 and from August to December 2014 in the UK, and from May to June 2013 and from May to June 2014 in the NL. All respondents were current smokers at time of enrolment. More details on the methods of the ITC data collection can be found in previous publications. ${ }^{24} 25$ Dropout between the two survey waves was $18 \%$ for the NL and $30 \%$ for the UK. In the current study, participants were selected of 18 years and older who participated in both waves and who smoked at least monthly in the 2013 survey. This formed a sample of $n=1164$ smokers from the NL, and $n=768$ from the UK.

\section{Free/lower cost medication as a trigger for thinking about quitting}

The main independent variable of this study was whether respondents mentioned free/lower cost smoking cessation medication as a trigger for thinking about quitting. This is referred to as 'free/lower cost medication as a trigger' in the remainder of this paper. It was measured in the 2013 surveys with the following question: 'In the past 6 months, has free, or lower cost, stopsmoking medication led you to think about quitting?'. ${ }^{17}$

The question was part of a list with four policy triggers, of which each could be selected independently from the others by the respondent. The other triggers (which were not the focus in this paper) were: the price of cigarettes, smoking restrictions in public places and warning labels on cigarette packages. Response options were: 'not at all', 'somewhat' and 'very much'. For the analyses, the response options were dichotomised: 'not at all' was classified as no trigger for thinking about quitting; 'somewhat' and 'very much' were classified as a positive trigger for thinking about quitting smoking.

\section{Use of smoking cessation medication}

Participants in both countries were asked in the 2014 surveys whether they had previously used smoking cessation medications. In the NL, respondents were asked about medication use in the last year while in the UK, medication use during the last quit attempt was assessed. Therefore, these survey items were not entirely comparable.

\section{Quit attempts and quit success}

To measure quit attempts, participants were asked the following question in the 2014 survey: 'Have you made any attempts (successful or not) to stop smoking in the last year?' Participants who responded affirmatively on this question were defined as having made a quit attempt. Successful quitters were defined as current smokers in 2013 who reported having made a quit attempt and not smoking at all or less than once a month in $2014 .^{26}$

\section{Income and education}

Respondents from the NL were asked about their monthly gross household income while UK respondents reported their annual gross household income. Response categories also differed between the two countries. The income variables were recoded into three categories based on tertiles in each country: defined as 'low' if income $<€ 2000$ (NL) or $<£ 15000$ (UK), 'moderate' if between $€ 2000$ and $€ 3000$ (NL) or between $£ 15000$ and $£ 30000$ (UK), and 'high' if $>€ 3000$ (NL) or $>£ 30000$ (UK). Respondents had the option not to disclose their income. These responses were treated as missing values. The level of education for both countries was recoded into three groups: 'low' for none completed, elementary school and lower secondary education; 'moderate' for secondary vocational education and middle secondary education; and 'high' for upper secondary education, university and postgraduate.

\section{Covariates}

Several covariates were used in the analyses, including gender and age (divided into four categories: 18-24 years, 25-39 years, 40-54 years, and 55 years and older). Nicotine dependence was measured by the Heaviness of Smoking Index (HSI). ${ }^{27} 28$ The HSI is a score ranging from 0 to 6 (low to high nicotine dependence) and is calculated based on both the number of cigarettes smoked per day and the time before smoking the first cigarette after waking up.

\section{Analyses}

IBM SPSS V.21.0 29 was used to analyse the data. Cross-sectional and longitudinal weights were calculated using age and gender for each country separately. ${ }^{24}$ Three multivariate logistic regression analyses were used to analyse the data. The associations were assessed between mentioning free/lower cost medication as a trigger to quit and (1) use of smoking cessation medication, (2) making a quit attempt and (3) smoking cessation 1 year later. Covariates in all analyses were gender, age and HSI. To account for possible 'time-in-sample' effects where answers from respondents who have participated in multiple survey waves vary from newly recruited respondents, ${ }^{30}$ analyses were adjusted for the respondents' number of times they participated in the survey. ${ }^{31}$ Two-way interactions between education and trigger and between income and trigger were included in the analyses. Due to between-country differences in data collection and survey items, analyses were conducted separately for the NL and the UK. As secondary analyses, the other three policy triggers (the price of cigarettes, smoking restrictions in public places and warning labels on cigarette packages) were added as independent variables in separate multivariate logistic regression analyses.

\section{RESULTS}

\section{Demographics}

The sociodemographic characteristics of the respondents are presented in table 1 . The UK research sample had a higher percentage $(53 \%)$ of high educated smokers than the NL $(25 \%)$ $(\mathrm{p}<0.001)$. In the NL, 30\% of respondents did not report their 
Table 1 Characteristics of participants in the first wave in the UK and the Netherlands (2013). Weighted data

\begin{tabular}{|c|c|c|c|}
\hline & UK & $\begin{array}{l}\text { The } \\
\text { Netherlands }\end{array}$ & Between-country \\
\hline & $(n=768)$ & $(n=1164)$ & differences \\
\hline Gender & & & \\
\hline Female (\%) & 48.6 & 49.3 & $\chi^{2}(1)=0.08$ \\
\hline & & & $\mathrm{P}=(0.777)$ \\
\hline Age & & & \\
\hline 18-24years (\%) & 11.9 & 12.8 & $\chi^{2}(3)=4.90$ \\
\hline 25-39years (\%) & 27.2 & 23.1 & $(P=0.179)$ \\
\hline 40-54 years (\%) & 33.4 & 33.4 & \\
\hline 55 years and older (\%) & 27.6 & 30.6 & \\
\hline Heaviness of Smoking Inde & & & \\
\hline $0-1(\%)$ & 27.5 & 29.6 & $\chi^{2}(2)=1.61$ \\
\hline $2-4(\%)$ & 65.8 & 63 & $(P=0.448)$ \\
\hline $5-6(\%)$ & 6.7 & 7.5 & \\
\hline Income level & & & \\
\hline Low (\%) & 28.5 & 22 & $\chi^{2}(2)=144.40$ \\
\hline Moderate (\%) & 31.7 & 20.1 & $(P<0.001)$ \\
\hline High (\%) & 32 & 27.8 & \\
\hline Not reported (\%) & 7.7 & 30.1 & \\
\hline Educational level & & & \\
\hline Low (\%) & 17.4 & 29.2 & $\chi^{2}(2)=146.59$ \\
\hline Moderate (\%) & 30.1 & 45.4 & $(\mathrm{P}<0.001)$ \\
\hline High (\%) & 52.5 & 25.4 & \\
\hline
\end{tabular}

household income, compared with $8 \%$ in the UK. Online supplementary appendix 1 shows medication use, quit attempts and quit success for respondents who did and who did not disclose their income. Smokers in both countries had a comparable level of nicotine dependence $(\mathrm{p}=0.448)$, with the largest group of respondents reporting an HSI between 2 and 4. Loss to follow-up was higher among younger participants in both countries and higher among lighter smokers in the UK (online supplementary appendix 2).
Table 2 Medication use, quit attempts and quit success within the entire sample and within respondents who mentioned free/lower cost medication as a trigger (weighted data)

\begin{tabular}{|c|c|c|c|c|c|c|}
\hline & \multicolumn{3}{|c|}{ Entire sample } & \multicolumn{3}{|c|}{$\begin{array}{l}\text { Mentioned free/lower cost } \\
\text { medication as a trigger }\end{array}$} \\
\hline & UK & $\mathrm{NL}$ & $P$ values & UK & NL & $P$ values \\
\hline Medication use (\%) & 39.8 & 20.1 & $<0.001$ & 54.8 & 31.2 & $<0.001$ \\
\hline Quit attempts (\%) & 43 & 32.7 & $<0.001$ & 48.2 & 36.2 & 0.003 \\
\hline Quit success (\%) & 35.2 & 28.5 & 0.064 & 34.1 & 19.3 & 0.014 \\
\hline
\end{tabular}

NL, Netherlands.

\section{Free/lower cost medication as a trigger for thinking about quitting}

In 2013, free/lower cost medication was mentioned as a trigger for thinking about quitting by $24.9 \%$ of the respondents in the NL and $37.0 \%$ of the respondents in the UK (results not shown in table). When comparing income groups, free/lower cost medication as a trigger was mentioned in the NL by $30.7 \%$ of low-income smokers compared with $20.9 \%$ of moderate-income smokers and $21.1 \%$ of high-income smokers $\left(\chi^{2}(2)=9.45\right.$, $\mathrm{p}=0.009)$. In the UK, free/lower cost medication as a trigger was mentioned by $40.2 \%, 33.6 \%$ and $39.2 \%$ of low, moderate and high-income groups, respectively $\left(\chi^{2}(2)=2.47, p=0.290\right)$. When education groups were compared, in the NL $28.8 \%$ of smokers with low education, $25.7 \%$ of smokers with moderate education and $21.2 \%$ of smokers with high education mentioned free/lower cost medication as a trigger $\left(\chi^{2}(2)=4.98, p=0.083\right)$. In the UK, $38.8 \%$ of smokers with low education, $41.1 \%$ of smokers with moderate education and $34.1 \%$ of smokers with high education mentioned free/lower cost medication as a trigger $\left(\chi^{2}(2)=3.17, p=0.205\right)$.

\section{Medication use}

In the NL, 31.2\% of smokers who made a quit attempt in the last year and mentioned free/lower cost medication as a trigger used smoking cessation medication in the last year compared with $15.8 \%$ who did not report this trigger $(\mathrm{p}=0.001$, figure 1 and

$$
\mathrm{P}=0.012
$$

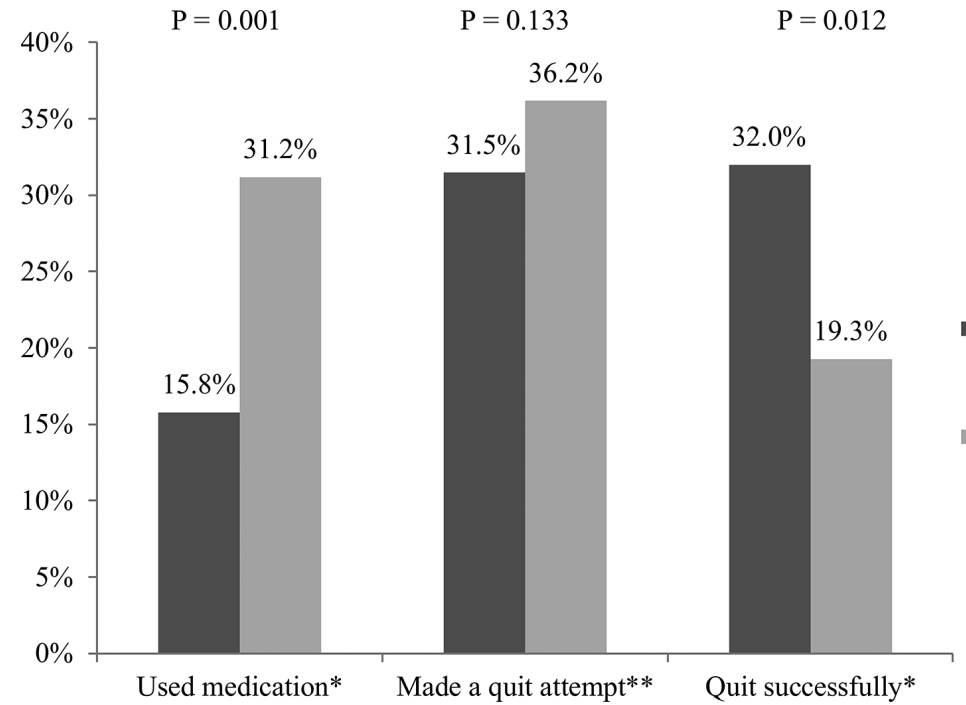

- Did not mention free medication as a trigger to quit smoking

Mentioned free medication as a trigger to quit smoking

Figure 1 Medication use, quit attempts and successful quitters among smokers who mentioned and smokers who did not mention free/lower cost medication as a trigger to think about quitting smoking in the Netherlands. *The denominator is all participants who made a quit attempt in the last year. ${ }^{* *}$ The denominator is all smokers. 


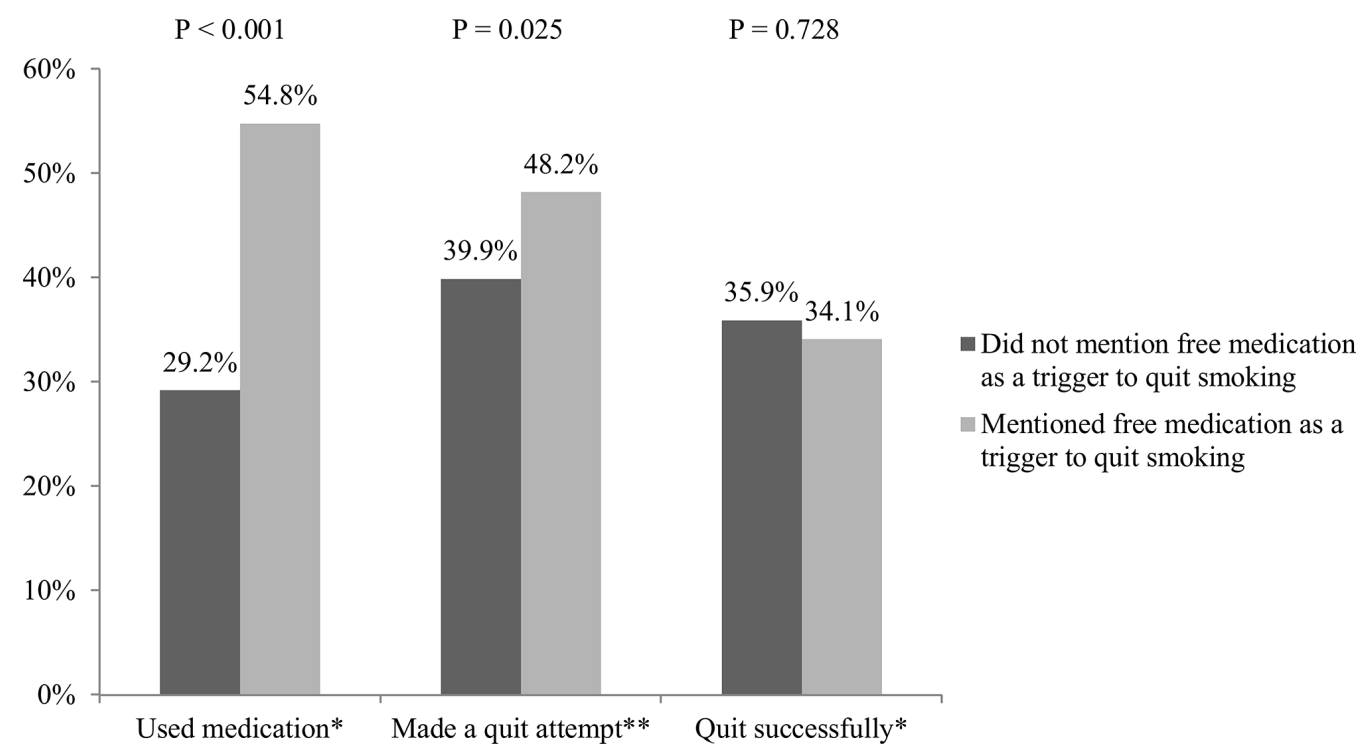

Figure 2 Medication use, quit attempts and successful quitters among smokers who mentioned and smokers who did not mention free/lower cost medication as a trigger to think about quitting smoking in the UK. *The denominator is all participants who made a quit attempt in the last year.

${ }^{* *}$ The denominator is all smokers.

table 2). In the UK, the medication use in the group of respondents that mentioned free/lower cost medication as a trigger was $54.8 \%$ compared with $29.2 \%$ in the group that did not report the trigger $(p<0.001$, figure 2$)$. Free/lower cost medication as a trigger was also positively associated with medication use in multivariate analyses both in the UK $(\mathrm{OR}=4.19, \mathrm{p}<0.001)$ and in the
NL $(\mathrm{OR}=2.14, \mathrm{p}=0.033) \quad$ (table 3$)$. The multivariate analyses showed no significant interactions between free/lower cost medication as a trigger, medication use and education and income groups. With the other policy triggers (smoking restrictions in public places, the price of cigarettes and warning labels on cigarette packages) added to the model, free/lower cost medication as

Table 3 Multivariate logistic regression analysest showing associations between free/lower cost cessation medication as a trigger for thinking about quitting smoking and medication use, quit attempts and quit success in the UK and the Netherlands (weighted data)

\begin{tabular}{|c|c|c|c|c|c|c|}
\hline & \multirow{2}{*}{\multicolumn{2}{|c|}{$\begin{array}{l}\text { Medication uset } \\
\text { OR }(95 \% \mathrm{Cl})\end{array}$}} & \multirow{2}{*}{\multicolumn{2}{|c|}{$\begin{array}{l}\text { Quit attempts } \\
\text { OR }(95 \% \mathrm{Cl})\end{array}$}} & \multicolumn{2}{|l|}{ Quit successt } \\
\hline & & & & & \multicolumn{2}{|l|}{ OR $(95 \% \mathrm{Cl})$} \\
\hline & UK & NL & UK & NL & UK & NL \\
\hline \multicolumn{7}{|l|}{ Gender } \\
\hline Female & 0.67 (0.38 to 1.19$)$ & $0.70(0.36$ to 1.35$)$ & $1.04(0.75$ to 1.44$)$ & 0.79 (0.59 to 1.07$)$ & $1.28(0.74$ to 2.20$)$ & $1.95(1.10 \text { to } 3.45)^{*}$ \\
\hline Male & 1 & 1 & 1 & 1 & 1 & 1 \\
\hline \multicolumn{7}{|l|}{ Age (years) } \\
\hline $18-24$ & $1.67(0.61$ to 4.58$)$ & $0.14(0.03 \text { to } 0.71)^{*}$ & $2.34(1.33 \text { to } 4.13)^{* *}$ & $1.18(0.71$ to 1.97$)$ & $0.60(0.23$ to 1.54$)$ & $0.33(0.10$ to 1.06$)$ \\
\hline $25-39$ & $0.97(0.42$ to 2.20$)$ & $0.53(0.22$ to 1.26$)$ & $1.89(1.19 \text { to } 3.00)^{* *}$ & $1.75(1.16 \text { to } 2.65)^{* *}$ & $0.78(0.36$ to 1.70$)$ & 0.95 (0.43 to 2.09$)$ \\
\hline $40-54$ & $0.66(0.28$ to 1.52$)$ & $1.21(0.55$ to 2.69$)$ & $1.27(0.82$ to 1.98$)$ & $1.04(0.70$ to 1.54$)$ & $0.69(0.32$ to 1.52$)$ & $1.11(0.52$ to 2.38$)$ \\
\hline $55+$ & 1 & 1 & 1 & 1 & 1 & 1 \\
\hline $\begin{array}{l}\text { Heaviness of Smoking } \\
\text { Index }\end{array}$ & 0.99 (0.83 to 1.19$)$ & $1.38(1.10 \text { to } 1.72)^{* *}$ & $0.96(0.86$ to 1.07$)$ & $0.88(0.79 \text { to } 0.97)^{*}$ & 0.85 (0.72 to 1.02$)$ & $0.74(0.61 \text { to } 0.90)^{* *}$ \\
\hline \multicolumn{7}{|l|}{ Trigger } \\
\hline Yes & $4.19(2.33 \text { to } 7.53)^{* * *}$ & 2.14 (1.07 to 4.29$)^{*}$ & $1.45(1.04 \text { to } 2.02)^{*}$ & $1.10(0.78$ to 1.56$)$ & 0.99 (0.58 to 1.68$)$ & $0.58(0.28$ to 1.20$)$ \\
\hline No & 1 & 1 & 1 & 1 & 1 & 1 \\
\hline \multicolumn{7}{|l|}{ Income level } \\
\hline Low & $1.47(0.70$ to 3.08$)$ & $1.68(0.77$ to 3.67$)$ & $0.76(0.50$ to 1.16$)$ & $1.12(0.78$ to 1.61$)$ & $0.65(0.32$ to 1.32$)$ & $0.45(0.23 \text { to } 0.90)^{*}$ \\
\hline Moderate & $0.64(0.32$ to 1.27$)$ & $2.00(0.89$ to 4.46$)$ & $0.74(0.50$ to 1.09$)$ & $0.74(0.51$ to 1.07$)$ & $0.62(0.33$ to 1.18$)$ & $0.43(0.21 \text { to } 0.88)^{*}$ \\
\hline High & 1 & 1 & 1 & 1 & 1 & 1 \\
\hline \multicolumn{7}{|l|}{ Education level } \\
\hline Low & $2.17(0.87$ to 5.46$)$ & 0.49 (0.19 to 1.22$)$ & $0.85(0.52$ to 1.38$)$ & $0.78(0.51$ to 1.20$)$ & 0.70 (0.29 to 1.68$)$ & 1.30 (0.56 to 2.98$)$ \\
\hline Moderate & $0.49(0.24 \text { to } 0.97)^{*}$ & $0.71(0.32$ to 1.56$)$ & $0.56(0.38 \text { to } 0.82)^{* *}$ & $0.84(0.59$ to 1.21$)$ & $0.53(0.27$ to 1.02$)$ & 1.11 (0.57 to 2.19$)$ \\
\hline High & 1 & 1 & 1 & 1 & 1 & 1 \\
\hline Time-in-sample & $0.85(0.76$ to 0.93$)$ * & 0.93 (0.80 to 1.07$)$ & $0.96(0.91$ to 1.02$)$ & $0.98(0.91$ to 1.05$)$ & $1.03(0.94$ to 1.13$)$ & 1.12 (0.98 to 1.28$)$ \\
\hline
\end{tabular}

${ }^{*} \mathrm{P}<0.05 ;{ }^{* *} \mathrm{P}<0.01 ;{ }^{* * *} \mathrm{P}<0.001$.

tOnly participants who made a quit attempt in the last year.

NL, Netherlands; Trigger, participant mentioned free/lower cost medication as a trigger for thinking about quitting smoking. 
a trigger was no longer significantly associated with medication use in the NL $(\mathrm{OR}=1.83, \mathrm{p}=0.113)$, but remained significant in the $\mathrm{UK}(\mathrm{OR}=4.26, \mathrm{p}<0.001)$ (results not shown in table).

\section{Quit attempts}

A bivariate analysis showed that $36.2 \%$ of respondents in the NL who mentioned free/lower cost medication as a trigger made at least one quit attempt between 2013 and 2014 compared with $31.5 \%$ who did not report this trigger $(p=0.133$, see figure 1$)$. In the UK, these numbers were $48.2 \%$ vs $39.9 \%(p=0.025$, see figure 2$)$. The multivariate analyses showed that in the UK, respondents who mentioned free/ lower cost medication as a trigger had a higher rate of quit attempts within the next year than those who did not report this trigger $(\mathrm{OR}=1.45, \mathrm{p}=0.030)$, but this association was not found in the NL $(\mathrm{OR}=1.10, \mathrm{p}=0.587$, see table 3$)$. There were no significant interactions between free/lower cost medication as a trigger and education and income levels for quit attempts in the multivariate analyses. When other policy triggers were added to the analysis as independent variables, free/ lower cost medication as a trigger was no longer significantly associated with quit attempts in the UK $(\mathrm{OR}=1.14, \mathrm{p}=0.489)$, and remained non-significant in the NL.

\section{Quit success}

Within the group of smokers who made a quit attempt, in the NL $19.3 \%$ of respondents who mentioned medication as a trigger quit smoking successfully compared with $32.0 \%$ who did not report this trigger $(p=0.012$, figure 1$)$. In the $U K$, this was $34.1 \%$ vs $35.9 \%(\mathrm{p}=0.728$, figure 2$)$. The multivariate analyses showed no significant association between free/lower cost medication as a trigger for thinking about quitting smoking and quit success (table 3). The analyses showed no significant interactions between free/lower cost medication as a trigger and quit success for different income and education levels. With the other three policy triggers added to the model, the association between free/lower cost medication as a trigger and quit success remained not significant.

\section{DISCUSSION}

The aim of this study was to investigate whether mentioning free/ lower cost medication as a trigger to think about quitting smoking was related to the use of cessation medication, quit attempts and quit success in the UK and the NL, and whether these associations were modified by education and income. The results showed a positive association between mentioning free/lower cost medication as a trigger and the use of smoking cessation medication in both the UK and the NL. This finding is in line with previous research, which showed that financial coverage leads to an increased utilisation of smoking cessation medication. ${ }^{15}$

Smokers who mentioned free/lower cost medication as a trigger for thinking about quitting smoking were more likely to have made a quit attempt a year later in the UK, but not in the NL. The association between free/lower cost medication as a trigger to quit smoking and quit attempts has also been demonstrated in Canada, the USA and Australia. ${ }^{18}$ The finding that there was no significant association between free/lower cost medication as a trigger and quit attempts in the NL may result from the difference in availability of free/ lower cost medication compared with the UK. The UK's stopsmoking services and health professionals provide subsidised medications for any smokers who want to quit, while in the NL health insurance reimbursement for smoking cessation medication is only available after a mandatory deductible amount is first spent. Not being able to receive free medication could demotivate smokers to follow through with their intended quit attempt. ${ }^{22} 32$

Smokers who mentioned free/lower cost medication as a trigger were not more likely to quit successfully which emphasises that it is a large step from contemplating quitting to actually achieving this goal. First, there may be barriers preventing smokers to start and sustain a quit attempt with medication, such as availability of free medication, self-efficacy and motivation. ${ }^{32-35}$ Likewise, many factors can influence whether a quit attempt leads to successful quitting. ${ }^{36}$ The current study did not investigate which hindering or promoting factors influence the relation between free/lower cost medication as a trigger and quit success, but further research focussing on this question could give important insights in how to achieve quit success in smokers who are triggered to think about quitting by free medication.

When the other policy triggers (smoking restrictions in public places, the price of cigarettes and warning labels on cigarette packages) were added to the analyses, the associations between free/lower cost medication as a trigger and the use of medication in the NL, and quit attempts in the UK were no longer significant. However, the association between free/lower cost medication as a trigger and the use of smoking cessation medication in the UK remained significant after correcting for the other policy triggers, which makes this the most robust finding of this study.

Another aim of this study was to investigate whether the income and education level of smokers influenced the association between mentioning free/lower cost medication as a trigger to quit smoking and use of cessation medications, quit attempts and quit success. Contrary to our hypothesis, the results showed that this association was not influenced by education or income level. This may mean that smokers with a lower SES as well as smokers with a higher SES who are triggered to think about quitting smoking by free cessation medication are equally likely to use medication, to make a quit attempt and potentially be successful in this attempt.

\section{Limitations}

This study has some limitations that should be taken into consideration. The validity of the survey question about whether respondents considered free/lower cost medication as a trigger to quit smoking was assumed but not investigated in this study. Loss to follow-up was higher among younger respondents in both countries, which could have influenced the results since research has shown that young adults were more likely to try quitting smoking, were more successful in quitting and were less likely to use cessation medication than older adults. ${ }^{37} 38$ The UK and NL data were not completely comparable since there were significant differences in income and education levels and differences in measuring the use of smoking cessation medication. In the UK, medication use was measured for the last quit attempt while in the NL it was measured for the last year. Therefore, the use of cessation medication may have predated the (by free medication triggered) thought about quitting smoking. In the UK, the lower education group was under-represented. In the NL, a large portion of the respondents did not disclose their income, which could have influenced the results if income was not equally distributed among these non-responders. Additionally, in the NL, data were collected by web questionnaires only and in the UK also by telephone. This difference in data collection could have affected survey outcomes but was expected to be of minor influence on the results of this study. ${ }^{39}$ 


\section{Practical implications}

This study found that smokers who considered free/lower cost medication as a trigger to quit smoking were more likely to actually use cessation medication, and that smokers from the UK were more likely to have attempted to quit smoking. To promote smoking cessation, it may therefore be beneficial to raise awareness of the availability of free cessation medication, for example, through mass media campaigns or healthcare providers.

The finding that the association between mentioning free/ lower cost medication as a trigger for thinking about quitting smoking and actual quit attempts was not influenced by education or income level suggests that free medication can motivate a large part of the smoking population to quit, and that this effect is not restricted to particular socioeconomic groups. Yet, since free medication is mentioned more often as a trigger to quit smoking by lower income smokers in the NL in the current study and in previous research also in the UK, Ireland and Germany, ${ }^{17}$ free medication may be an important strategy to decrease the socioeconomic gap in smoking.

\section{CONCLUSION}

Considering free/lower cost smoking cessation medication as a trigger for thinking about quitting smoking could, irrespective of smokers' income or education, be positively associated with quit attempts and may promote the use of cessation medication during this attempt. Therefore, making cessation medication freely accessible to smokers may be an important strategy to decrease smoking in the population.

Correction notice This article has been corrected since it was published Online First. The funding statement was incorrect.

Acknowledgements Parts of this paper appeared in the thesis of coauthor $\mathrm{KH}$, which was also published as an article (see ref 17). We thank the ITC Project (University of Waterloo) for their contribution in project management, survey development and data cleaning.

Contributors $F A B$ and GEN conducted the statistical analyses together and $F A B$ drafted the manuscript. All authors contributed to the writing of the manuscript and revised and approved the final manuscript.

Funding The ITC Netherlands Surveys were supported by grants from the Netherlands Organisation for Health Research and Development (ZonMw \#200130002). The ITC UK Surveys were supported by grants R01 CA 100362 and P01 CA138389 from the National Cancer Institute of the USA, Canadian Institutes of Health Research (MOP-115016).

Competing interests None declared.

\section{What this paper adds}

In previous research, free/lower cost smoking cessation treatment has shown to be a trigger for thinking about quitting smoking for smokers with a lower education and income and this trigger was positively associated with making a quit attempt.

- It has been unclear whether mentioning free/lower cost medication as a trigger for thinking about quitting was associated with actual use of cessation medication and quit success and whether this association was dependent on smokers' income or education.

- This study showed that mentioning free/lower cost medication as a trigger for thinking about quitting smoking was positively associated with quit attempts in the UK and promoted the use of cessation medication in both the Netherlands and the UK, irrespective of smokers' education or income.
Patient consent Detail has been removed from this case description/these case descriptions to ensure anonymity. The editors and reviewers have seen the detailed information available and are satisfied that the information backs up the case the authors are making.

Ethics approval The survey protocols and all materials, including the survey questionnaires, were cleared for ethics by Research Ethics Office, King's College London, UK; Office of Research Ethics, University of Waterloo, Canada for ITC UK Surveys and Office of Research Ethics, University of Waterloo, Canada for ITC Netherlands Surveys.

Provenance and peer review Not commissioned; externally peer reviewed. Data sharing statement No additional data available.

(c) Article author(s) (or their employer(s) unless otherwise stated in the text of the article) 2019. All rights reserved. No commercial use is permitted unless otherwise expressly granted.

\section{REFERENCES}

1 Reid JL, Hammond D, Boudreau C, et al. Socioeconomic disparities in quit intentions, quit attempts, and smoking abstinence among smokers in four western countries: findings from the International Tobacco Control Four Country Survey. Nicotine Tob Res 2010;12(Suppl):S20-33.

2 Hiscock R, Bauld L, Amos A, et al. Smoking and socioeconomic status in England: the rise of the never smoker and the disadvantaged smoker. J Public Health 2012:34:390-6.

3 Nagelhout GE, de Korte-de Boer D, Kunst AE, et al. Trends in socioeconomic inequalities in smoking prevalence, consumption, initiation, and cessation between 2001 and 2008 in the Netherlands. Findings from a national population survey. BMC Public Health 2012;12:1-9.

4 Huisman M, Kunst AE, Mackenbach JP. Inequalities in the prevalence of smoking in the European Union: comparing education and income. Prev Med 2005;40:756-64.

5 Schaap MM, Kunst AE. Monitoring of socio-economic inequalities in smoking: learning from the experiences of recent scientific studies. Public Health 2009;123:103-9.

6 Siahpush M, English D, Powles J. The contribution of smoking to socioeconomic differentials in mortality: results from the Melbourne collaborative cohort study, Australia. J Epidemiol Community Health 2006:60:1077-9.

7 Jha P, Peto R, Zatonski W, et al. Social inequalities in male mortality, and in male mortality from smoking: indirect estimation from national death rates in England and Wales, Poland, and North America. Lancet 2006;368:367-70.

8 Giskes K, Kunst AE, Benach J, et al. Trends in smoking behaviour between 1985 and 2000 in nine European countries by education. J Epidemiol Community Health 2005;59:395-401.

9 Gielkens-Sijstermans CM, Mommers MA, Hoogenveen RT, et al. Reduction of smoking in Dutch adolescents over the past decade and its health gains: a repeated crosssectional study. Eur J Public Health 2010;20:146-50.

10 Harper S, Lynch J. Trends in socioeconomic inequalities in adult health behaviors among U.S. states, 1990-2004. Public Health Rep 2007:122:177-89.

11 Federico B, Costa G, Kunst AE. Educational inequalities in initiation, cessation, and prevalence of smoking among 3 Italian birth cohorts. Am J Public Health 2007; $97: 838-45$

12 Office for National Statistics. Dataset: smoking habits in the UK and its constituent countries: Office for National Statistics, 2016

13 Verdurmen J, Monshouwer K, Van Laar M, et al. Factsheet continu onderzoek rookgewoonten 2013. Utrecht: Trimbos-instituut, 2014.

14 Roddy E, Antoniak M, Britton J, et al. Barriers and motivators to gaining access to smoking cessation services amongst deprived smokers--a qualitative study. BMC Health Serv Res 2006;6:147.

15 van den Brand FA, Nagelhout GE, Reda AA, et al. Healthcare financing systems for increasing the use of tobacco dependence treatment. Cochrane Database Syst Rev 2017:9:CD004305.

16 Kaper J, Wagena EJ, Willemsen MC, et al. Reimbursement for smoking cessation treatment may double the abstinence rate: results of a randomized trial. Addiction 2005; 100:1012-20.

17 Hummel K, Nagelhout GE, Willemsen MC, et al. Trends and socioeconomic differences in policy triggers for thinking about quitting smoking: findings from the International Tobacco Control (ITC) Europe surveys. Drug Alcohol Depend 2015;155:154-62.

18 Kasza KA, Hyland AJ, Borland R, et al. Cross-country comparison of smokers' reasons for thinking about quitting over time: findings from the International Tobacco Control Four Country Survey (ITC-4C), 2002-2015. Tob Control 2017;26.

19 Bauld L, Bell K, McCullough L, et al. The effectiveness of NHS smoking cessation services: a systematic review. J Public Health 2010;32-71-82.

20 National Health Service. NHS smoke free. London: National Health Service.

21 NCSCT. Standard treatment programme. A guide to providing behavioural support for smoking cessation London. London: National Centre for Smoking Cessation and Training, 2014. 
22 Rosenthal L, Carroll-Scott A, Earnshaw VA, et al. Targeting cessation: understanding barriers and motivations to quitting among urban adult daily tobacco smokers. Addict Behav 2013;38:1639-42.

23 Bryant J, Bonevski B, Paul C, et al. Developing cessation interventions for the social and community service setting: a qualitative study of barriers to quitting among disadvantaged Australian smokers. BMC Public Health 2011;11:493.

24 Thompson ME, Fong GT, Hammond D, et al. Methods of the International Tobacco Control (ITC) four country survey. Tob Control 2006;15(Suppl 3):iii12-iii18.

25 Zethof $D$, Nagelhout GE, de Rooij M, et al. Attrition analysed in five waves of a longitudinal yearly survey of smokers: findings from the ITC Netherlands survey. Eur J Public Health 2016;26:693-9.

26 Hyland A, Borland R, Li Q, et al. Individual-level predictors of cessation behaviours among participants in the International Tobacco Control (ITC) Four Country Survey. Tob Control 2006;15(Suppl 3):iii83-iii94.

27 Heatherton TF, Kozlowski LT, Frecker RC, et al. The fagerström test for nicotine dependence: a revision of the fagerström tolerance questionnaire. $\mathrm{Br} J$ Addict 1991;86:1119-27.

28 Heatherton TF, Kozlowski LT, Frecker RC, et al. Measuring the heaviness of smoking: using self-reported time to the first cigarette of the day and number of cigarettes smoked per day. Br J Addict 1989;84:791-800.

29 Corp IBM. IBM SPSS statistics for windows, Version 21.0. Armonk, NY: IBM Corp, 2012.

30 Thompson ME. Using longitudinal complex survey data. Annu Rev Stat Appl 2015;2:305-20.

31 Driezen P, Thompson M. Comparing policy measures across multiple ITC countries: Adjusting for time-in-sample. Canada: University of Waterloo, 2011.
32 Smith AL, Carter SM, Chapman S, et al. Why do smokers try to quit without medication or counselling? A qualitative study with ex-smokers. BMJ Open 2015;5:e007301.

33 Jardin BF, Cropsey KL, Wahlquist AE, et al. Evaluating the effect of access to free medication to quit smoking: a clinical trial testing the role of motivation. Nicotine Tob Res 2014;16:992-9.

34 Twyman L, Bonevski B, Paul C, et al. Perceived barriers to smoking cessation in selected vulnerable groups: a systematic review of the qualitative and quantitative literature. BMJ Open 2014;4:e006414.

35 Gwaltney CJ, Metrik J, Kahler CW, et al. Self-efficacy and smoking cessation: a metaanalysis. Psychol Addict Behav 2009;23:56-66.

36 Vangeli E, Stapleton J, Smit ES, et al. Predictors of attempts to stop smoking and their success in adult general population samples: a systematic review. Addiction 2011;106:2110-21.

37 Messer K, Trinidad DR, Al-Delaimy WK, et al. Smoking cessation rates in the United States: a comparison of young adult and older smokers. Am J Public Health 2008;98:317-22.

38 Curry SJ, Sporer AK, Pugach O, et al. Use of tobacco cessation treatments among young adult smokers: 2005 National Health Interview Survey. Am J Public Health 2007;97:1464-9.

39 Nagelhout GE, Willemsen MC, Thompson ME, et al. Is web interviewing a good alternative to telephone interviewing? Findings from the International Tobacco Control (ITC) Netherlands survey. BMC Public Health 2010;10:351. 